\section{El enfoque multidisciplinario: un desafío pedagógico en la Enseñanza de la Moda y el Diseño}

Marcia Veneziani *

\begin{abstract}
Resumen: Los estudios de la moda requieren continuamente un abordaje a partir de reflexiones y enfoques multidisciplinarios. Los textos de los académicos argentinos que se incluyen en este Cuaderno, evidencian la necesidad de profundizar cada vez más en disciplinas que rebasan y al mismo tiempo conciernen al ámbito específico de la moda y el diseño. En una profesión altamente competitiva y de gran visibilidad, como lo es el diseño en todas sus formas, se torna más que necesaria la inclinación por los estudios del arte, la historia, la psicología, la fotografía, la sociología, la antropología, la comunicación, la filosofía, la economía y la ecología entre otras, más allá de las tendencias ocasionales y pasajeras. La moda y todas aquellas disciplinas imbricadas en el mundo del diseño en general, se encuentran atravesadas por un sinfín de entramados que buscan encontrar respuestas a comportamientos y a la lógica comercial allende a lo puramente pasajero. Por lo tanto, la investigación se torna central a la hora de pensar la moda, y al mismo tiempo, la inserción en el mundo laboral requiere del estudio de casos y de estrategias que respondan al contexto y a los desafíos que los tiempos actuales presentan.
\end{abstract}

Palabras clave: códigos culturales - desafíos pedagógicos - diseño de indumentaria - enseñanza del diseño - identidad - multidisciplinario.

[Resúmenes en inglés y portugués en la página 22]

${ }^{(*)}$ Doctora en Ciencias de la Comunicación Social y Licenciada en Publicidad por la Universidad del Salvador. Docente Titular de la Universidad de Palermo en el Departamento de Investigación y Producción de la Facultad de Diseño y Comunicación. [Ver CV completo en página 205]

Los estudios de la moda requieren continuamente un abordaje a partir de reflexiones y enfoques multidisciplinarios. Por ende, los desafíos pedagógicos se tornan cada vez más complejos. Los textos de los académicos argentinos que aquí se publican, tienen algunos puntos de convergencia con aquellos de los norteamericanos, más allá de los códigos culturales comunes o heterogéneos. Es decir, evidencian la necesidad de profundizar cada vez más en disciplinas que rebasan y al mismo tiempo conciernen al ámbito específico de la moda y el diseño. 
Así, las modas, estilos de vida, consumo y estereotipos difundidos por los medios de comunicación, no transitan sin dejar huella en ambas sociedades, invitando a la emulación a través de ritos de comportamientos cotidianos. La identidad convertida en un híbrido se torna en un punto central a la hora de pensar el diseño inserto en un contexto cada día más cambiante, y paradójicamente y en simultáneo, semejante en variados aspectos (a pesar de las respectivas individualidades que bregan por diferenciarse en un mundo globalizado).

En una profesión altamente competitiva y de gran visibilidad (como lo es el diseño en todas sus formas) se torna más que necesaria la inclinación por los estudios del arte, la historia, la psicología, la fotografía, la sociología, la antropología, la comunicación, la filosofía, la economía y la ecología entre otras, más allá de las tendencias ocasionales y pasajeras. La moda y todas aquellas disciplinas imbricadas en el mundo del diseño en general, se encuentran atravesadas por un sinfín de entramados que buscan encontrar respuestas a comportamientos y a la lógica comercial allende a lo puramente pasajero. Por lo tanto, la investigación se torna central a la hora de pensar la moda, y al mismo tiempo, la inserción en el mundo laboral requiere del estudio de casos y de estrategias que respondan al contexto y a los desafíos que los tiempos actuales presentan.

Precisamente, Marcia Veneziani en su artículo Costumbres, dinero y códigos culturales: conceptos inseparables para la enseñanza del sistema de la moda a partir de profundos estudios de diferentes autores y épocas sostiene que en la enseñanza de los estudios de moda y su consumo, es primordial el enfoque multidisciplinario con el fin de comprender el denominado sistema de la moda. Para ello, profundiza en las teorías de Ortega y Gasset, Thorstein Veblen y Clotaire Rapaille. En el ensayo, se consideran los denominados "códigos culturales" de europeos y americanos para luego intentar descifrar si existen tales que se adapten al estilo consumista argentino. Unos y otros, si bien con diferentes códigos y proyectados hacia diferentes objetos, servicios o estilos, responderían básicamente a una matriz de comportamiento de acuerdo a su propio contexto y cultura.

Así, Leandro Allochis en De New York a Buenos Aires y del Hip Hop a la Cumbia Villera. El protagonismo de la imagen en los procesos de transculturación a través de un estudio de caso sostiene que las representaciones trascienden como nunca antes sus territorios y grupos culturales de origen a causa de la globalización. Para su análisis, el autor analiza fotografías de músicos en busca de patrones de imitación y consumo asimiladas en diversas poblaciones. A través de imágenes de la cultura musical del Hip Hop norteamericano y de la denominada Cumbia Villera Argentina, intenta mostrar similitudes e hibridaciones estéticas. Para ello, encuadra concisamente los contextos socio-históricos que rodean a cada uno de estos grupos culturales.

De comunidades y cultura también se ocupa María Ximena González Eliçabe quien a través de relatos de chamanes y ropajes, mezcla ritos tradicionales con performances de artistas como Joseph Beuys, Louise Burgeois, Lygia Clark, Hélio Oiticica y Nick Cave. En su artículo da cuenta de la vinculación de prácticas ancestrales con aquellas del diario vestir. La vestimenta como hábitat es uno de sus temas centrales y para ello se vale de las palabras de Viveiros de Castro: "Para poder mudar de formas, independientemente de si las formas transforman al espíritu o viceversa, hay que suponer una esfera en la cual esta permutabilidad pueda transcurrir y donde se puedan influenciar mutuamente". 
A influencias y entramados culturales se refiere Laureano Mon en Los caminos de la innovación en la Argentina. El autor se adentró en el corazón de dos regiones de nuestro país: el noroeste -que incluye las provincias de Salta, Jujuy, Tucumán, Santiago del Estero y Catamarca- y el noreste -comprendida por Misiones, Corrientes, Chaco y Formosa. El escrito relata acerca de numerosos diseñadores que han producido piezas originales, combinando y reinterpretando su entorno, tanto productivo como cultural. "Los límites se cruzan en una urgencia por imaginar trayectos inéditos" y por ende, la innovación comprende no sólo los aspectos constructivos, estéticos y funcionales de los productos, sino también evidencia simbologías de su cultura y entorno. Así, en el hacer, se mezclan las tradiciones culturales de los pueblos con los métodos industriales y "las piezas de diseño adquieren, entonces, una trazabilidad compleja que integra en su concepción aspectos racionales y emocionales".

Sofía Marré por su parte, en El asociativismo en las empresas de diseño de indumentaria de autor en Argentina presenta al asociativismo como una estrategia novedosa y creativa de cooperación que permite a las micro, pequeñas y medianas empresas de diseño de autor argentino obtener beneficios en contextos complejos. Estos acuerdos entre productores permiten que cada uno de ellos mantenga su independencia jurídica pero a la vez "voluntariamente participe en un esfuerzo conjunto con los otros participantes para la búsqueda de un objetivo común”. La autora entrevista a referentes del sector con el fin de mostrar cómo la acción conjunta "fortalece a la asociación y facilita el delineamiento de políticas acorde a las necesidades" de cada uno de los integrantes de los diferentes proyectos.

En relación a la pedagogía del diseño en el aula, y con la intención de entender el proceso proyectual que se desarrolla en el aprendizaje de la materia central de la carrera Diseño de Indumentaria, Patricia Doria en su escrito Sobre la Enseñanza del Diseño de Indumentaria. El desafío creativo (enseñanza del método) aborda la cuestión explicando las diversas etapas del mismo. Con esa finalidad, analiza las diferentes fases por las que atraviesan los estudiantes. Para la autora los proyectos “... responden a un concepto de diseño vinculado también a las formas de producción industrial y sobre todo a formar individuos creativos que conozcan las necesidades de la cultura y la tecnología necesaria en posibles y futuros mercados". Remarca como fundamental en el proceso, una práctica interdisciplinaria obligada. La enseñanza de la ética en relación al diseño sustentable se presenta como urgente para Maximiliano Zito, quien con una mirada lúcida en su artículo La ética del diseño sustentable, cuestiona el consumismo desmedido y pregona: "entender el problema implica preguntarnos como especie de manera sincera si estamos dispuestos a asumir el sacrificio que implica volver a ritmos de explotación del planeta acorde a la tasa de regeneración que tengan sus recursos". El autor sostiene que el diseñador industrial debería plantearse su participación en el proceso de la industrialización, conociendo que con su labor mantiene una dirección no sustentable del mundo. Y remata: "pero ese cuestionamiento ético, ¿alcanza para evitar que siga con su trabajo? Es más, ¿quién desde afuera se atrevería a cuestionarle su participación en dicha industria?"

He aquí pues, una serie de ensayos que exponen las miradas de las distintas escuelas del diseño con el fin de brindar un aporte y al mismo tiempo evidenciar (al menos en parte) el modo polifacético en que se aborda en la actualidad la enseñanza de las respectivas disciplinas. 
Summary: Fashion education continually requires an approach from reflections and multidisciplinary approaches. The argentine academic texts included in this journal, show the need to go deeper and deeper in those disciplines that go beyond while concerning the specific field of fashion and design. In a highly competitive profession, highly visible, as is the design in all its forms, it becomes more necessary inclination for art studies, history, psychology, photography, sociology, anthropology, communication, philosophy, economics and ecology among others, beyond occasional and fleeting trends. Fashion and all disciplines embedded in the design world in general, are crossed by a myriad of frameworks that seek to find answers to behaviors and business logic beyond the purely fleeting. Therefore, research becomes central when thinking fashion, and at the same time, the inclusion in the workplace requires case studies and strategies that respond to the context and the challenges presented by modern times

Keywords: cultural codes - fashion design - fashion design education - identity - multidisciplinary - pedagogical challenges.

Resumo: Os estudos da moda requerem continuamente uma abordagem a partir de reflexões e enfoques multidisciplinares. Os textos dos acadêmicos argentinos que se incluem neste Caderno, evidenciam a necessidade de aprofundar cada vez mais em outras disciplinas e ao mesmo tempo tem relação com o campo específico da moda e o design. Numa profissão altamente competitiva e de muita exposição, como é o design em todas suas formas, torna-se mais que necessária a inclinação pelos estudos da arte, da história, da psicologia, da fotografia, da psicologia, da antropologia, da comunicação, da filosofia, da economia e da ecologia entre outras, além das tendências ocasionais e passageiras. A moda e todas aquelas disciplinas relativas ao design, encontram-se atravessadas por infinitas tramas que procuram encontrar respostas a comportamentos e à lógica comercial além aquilo puramente passageiro. Assim, a pesquisa é fundamental na hora de pensar a moda, e, ao tempo, a inserção no mundo laboral precisa do estudo de casos e de estratégias que respondam ao contexto e aos desafios que os tempos atuais apresentam.

Palavras chave: códigos culturais - desafios pedagógicos - design de indumentária - ensino do design - identidade - multidisciplinar. 